Seito

XV. Gerichtliche Verbote; Beschlagnahmen . . . . . . . . 57

Gerichtliche Verbote . . . . . . . . . . . . 57

Beschlagnahmen. . . . . . . . . . . . . 59

\title{
Anhang.
}

(Die Gesetzes- und Verordnungstexte sind nur insoweit in der Obersetzung wiedergegeben, als sie für die vorliegende Arbeit interessieren.)

I. Parliamentary Papers Act 1840 . . .

2. Lord Campbell's Libel Act 1843 . . . . . . . 61

3. Newspapers, Printers and Reading Rooms Repeal Act 186964

4. Newspeper Libel and Registration Act 1881 . . . . . . 66

5. Law of Libel Amendment Act 1888 . . . . . . . 70

6. Finance Act 1907 . . . . . . . . . . . . . . . . 72

7. Local Authorities (Admission of the Press to Meetings) Act 1908 . . . . . . . . . . . . . . . . . . . . 72

8. Children Act 1908 . . . . . . . . . . . . . . . . . . . . $\quad 73$

9. Copyright Act 1911 . . . . . . . . . . . . . . . . . 73

10. Defence of the Realm (consolidation) Regulations 1914 . . 75

11. Larceny Act 1916 . . . . . . . . . . . . . . 76

12. Criminal Justice Act 1925 . . . . . . . . . . . . . . 76

13. Judicial Proceedings (Regulation of Reports) Act 1926 . . 77

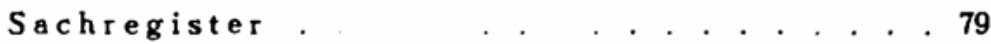

\section{Verzeichnis der im Text angeführten, aber im Anhang nicht wiedergegebenen Gesetze und Verordnungen.}

Fox's Libel Act 1792

Incitement to Mutiny Act 1797 . . . . . . . . . . . . . . 15

Blasphemous and Seditious Libels Act 1819/20 . . . . . . 14

Lotteries Act 1823 . . . . . . . . . . . . . . . . . . . . . 51

Lotteries Act 1836 . . . . . . . . . . . . . . . . . 52

The Libel Act 1845 . . . . $\quad$. . . . . . . . . . . 33

Art Unions' Act 1846 . . . . . . $\quad$. . . . . . . . 52

Betting Act 1853 . . . . . . . . . . . . . . . . . . 52

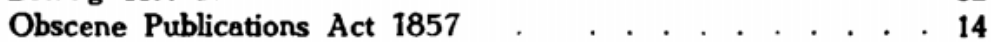

Larceny Act 1861 . . . . . . . . . . . . . . . . . 51

Larceny (Advertisements) Act 1870 . . . . . . . . . . . 51

Betting Act 1874 . . . . . . . . . . . . . . . . . . 52

Cruelty to Animals Act 1876 . . . . . . . . . . . . . . . . 52 
Seito

Corrupt and Illegal Practices Act 1883 . . . . . . . . . . . . 49

Stamp Act 1891 . . . . . . . . . . . . . . . . . . . 45

Corrupt and Ilegal Practices Prevention Act 1895 . . . . . . . 57

Musical Copyright Act 1906 . . . . . . . . . . . . . . . . 59

Trade Disputes Act 1906 . . . . . . . . . . . . . . . . 30

Patents and Designs Act 1907 . . . . . . . . . . . 26. 29, 58

Post Office Act 1908 . . . . . . . . . . . . . . . . . . . . . . 44

Municipal Elections (Corrupt and Illegal Practices Act 1911) . . 49

Copyright Act 1911, Sec. 6 . . . . . . . . . . . . . . 58

Copyright Act 1911. Sec. 11 . . . . . . . . . . . . . . . . . 59

Official Secrets Act 1911 . . . . . . . . . . . . . . . 4, 15

Post Office Act 1913 . . . . . . . . . . . . . . . . . . . . . . . . 44

Defence of the Realm Act 1914 . . . . . . . . . . . . . . . . 40

Venereal Diseases Act 1917 . . . . . . . . . . . . . . 50

Representation of the People Act 1918 . . . . . . . . . . 50

Emergency Powers Act 1920 . . . . . . . . . . . . . . . 43

Ready Money Football Betting Act 1920 . . . . . . . . . 52

Official Secrets Act 1920 . . . . . . . . . . . . . . . . 15

Emergency Regulations $1926^{\circ}$. . . . . . . . . . . . . . 43

\section{Verzeichnis der angeführten Entscheidungen.}

Adam v. Ward (1917) . . . . . . . . . . . . . . . . . . . . . . 19

Aga Khan, The, v. Times Publ. Co. (1924) . . . . . . . . . . 8, 24

Allbutt v. General Medical Council (1889) . . . . . . . . . . 17

Arnold v. King-Emperor of India (1914) . . . . . . . . . . . . . 2

Atkins v. Perrin (1862) . . . . . . . . . . . . . . . . 25

Re Bahama Islands (1893) . . . . . . . . . . . . . . . . 48

Batten v. Pall Mall Deposit \& Forwarding Co., Ltd. (1927) . . 31

Bishop v. Latimer (1811) . . . . . . . . . . . . . . . . 16

Bonnard v. Perryman (1891) . . . . . . . . . . . . . . . 57

Borthwick v. Evening Post (1887) . . . . . . . . . . . . . . 58

Bowman v. Secular Society Ltd. (1917) . . . . . . . . . . 13

Boydell v. Jones (1838) . . . . . . . . . . . . . . . . . 8

Capital \& Counties Bank v. Henty (1882) . . . . . . . . . 8

Champion \& Co. v. Birmingham Vinegar Brewery Co. Ltd. (1893) 57

Chatterton v. Sec. of State for India (1895) . . . . . . . . . . 16

Chesshire v. Strauss (1896) . . . . . . . . . . . . . . . . 48

Citizens' Life Assurance Co. Ltd. v. Brown (1904) . . . . . . . 27

Coleman v. West Hartlepool Harbour \& Ry. Co. (1860) . . . . 58

Collard v. Marshall (1892) . . . . . . . . . . . . . . . 57

Dicks v. Brooks (1880) . . . . . . . . . . . . . . . . . . . 25

Duke of Brunswick v. Harmer (1849) . . . . . . . . . . . 38 